\title{
An Analysis of Male Undergraduates' Career - seeking Motivation and Its Characteristics
}

\author{
Lixia Wang \\ Yunnan University of Traditional Chinese Medicine, Kunming, Yunnan, \\ 650500
}

\begin{abstract}
With the advancement of science and technology, people's health needs increase and nursing professional development. Men in the nursing profession more and more show their superiority. More and more medical colleges and hospitals began to develop, accept and use male nurses. To encourage more men to join the nursing team to the professional values of individual values in general is the embodiment of professional life. It not only determines the people's career choice and work attitude. It has great influence on people's career choice, work target, effort level and self-realization. It is also the basis for nursing educators to understand their attitudes and motivations. In this paper, qualitative research methods of nursing undergraduate professional values of the status quo and related factors to explore. To understand the boys this is a special group of professional nursing concept and its personal, social and professional factors of their own. It guides the boys to set up the correct nursing professional values. training senior male nursing talent.
\end{abstract}

Keywords: Male Undergraduate, Career Seeking, Charateristics

\section{Introduction}

With the development of society, nursing has become a high-tech, scientific research work, is no longer a single-sex work, which makes men re-enter the nursing field possible. So the number of male nurses in recent years has been increasing trend. People through their own contacts, see the strengths of men than women, and gradually recognize them and accept them. In the questionnaire 
survey of 682 health care workers, patients and their families in 5 hospitals in Guangzhou, $84.3 \%$ of the patients and their families were able to accept nursing care of male nurses, $90.5 \%$ of male and $80.7 \%$ of females indicated that they could accept male nurses Despite this, the number of male nurses is far less than female. And they apply for nursing reasons for socio-economic changes. Yang Xueqin and Zhang Ying, who survey shows that most of the boys choose nursing professional motivation is easy to obtain employment and high acceptance rate and employment rate. This is closely related to the present employment situation of students and the utilitarian career motive and professional pursuit of apathy. Career choice of contemporary college students is the impact of social change and shock, showing a distinctive feature of the times.

\section{Research steps}

Establish preliminary plans, clarify research objectives, determine the scope of the study; establish analytical methods; collect and collate data, the establishment of the database, the correct choice of statistical analysis. Analyze the statistical results and discuss; make recommendations.

$(\mathrm{E})$, neuroticism $(\mathrm{N})$, psychoticism $(\mathrm{P})$, disguise (L), and self-esteem (EPQ) were used in this study, which were divided into four subscales: , A total of 88 questions, answer "yes" or "no", according to 1, 0 points. Eysenck Personality Questionnaire $\mathrm{L} \geqslant 15$ points for the waste volume. $\mathrm{RE}=0.67, \mathrm{rE}=087, \mathrm{rN}=$ $0.92, \mathrm{rL}=0.80$ for women, $\mathrm{rP}=0.70, \mathrm{rE}=0.92, \mathrm{rN}=0.88$ and $\mathrm{rL}=0.69$ for men. The questionnaire is widely used in our country, and it is thought that Eysenck 's EPQ is well preserved and has good reliability and validity. Holland Occupational Interest Test is a famous career guidance expert John Holland based on his theory of personality type theory, formerly known as the Self-Career Choice Scale (Self-Directed Search, SDS). SDS, in line with Holland's RLASEC concept, is a career counseling tool for self-management, scoring, and revealing results that can be used to effectively assess individual differences in career interests. Unlike other standardized psychometric tests, the SDS does not need to be modeled by the population. Its score is very simple. As long as the total score of the six interest categories is calculated, the top-ranked types Representative of the most typical subjects of interest, the subjects have the typical characteristics of the type. SDS in the United States, Canada, Japan, Australia and other countries is widely used, and a special publishing company to issue such a test. With the development of China's market economy, people are more and more opportunities to choose their own jobs, China's vocational guidance activities are also in-depth development, some scholars have introduced this test and revision, some scholars have tested this test and adaptation .

All the data were analyzed by SPSS13.0 statistical software after establishing the database input data. Statistical methods include: t test, one-way ANOVA, correlation analysis, regression analysis. $\mathrm{P}<0.05$ was considered statistically significant. 


\section{Analysis on Career Attitude and Personality Characteristics of Nursing}

Among those who choose to pursue careers, those who like to choose nursing profession voluntarily are $5.9 \%$, and those who improve their character are $2.97 \%$. Although they are few in number, these people will become the important source of male nurses through professional quality education. Schools should pay attention to the professional thinking of these students, cultivate a good professional personality, to promote the successful completion of the social role of the conversion. Nursing education is expected to be further developed to retain more men. The survey results, the family recommended the choice of nursing professional ranks third. Most of the students in the 19-23 year-old youth, this stage some of the students understanding of the occupation is not yet mature, can not choose their own jobs, family views on them. Career motivation is the tendency of motive in the performance of career choice, is the career choice of college students and career motive force. Employment phenomenon in recent years shows that college students' career behavior is affected by the socioeconomic situation, the performance of career motivation is the first employment and then consider their own career interests.

But the data still intuitively shows, because of the high employment rate and select nursing profession than the adjustment and other motivators are more outward, neurotic score high, performance for more optimistic, more active good personality. It shows that the students who choose nursing specialty because of their high employment rate have clear and positive motive of choosing career and meet the requirement of historical progress. It reflects the practicability, adaptability and sociality of career choice, and also shows that these students can change their roles well to adapt to changes in the social environment. Although the personality factors affect the formation of motivation, but because of the reality of various subjective and objective factors, the existence of their own and external obstacles, college students "self-employment" form of vocational choice is restricted.

This study shows that the professional interest of nursing undergraduates is social type. This type of personality is helpful to the students, easy to cooperate, strong sense of responsibility, interested in social problems, interested in education and social welfare, Treatment and social welfare undertakings. It shows that the personality type of nurses meet the type of nursing profession, students can adapt to the nursing profession well, and can play their own talents after work. The study also shows that occupational interest scores second to the social type is the enterprise type and research type, these two groups of personality characteristics of self-confidence, like the management and control of others, good at engaging in responsible, risky work and independent, prudent, Like the work of scientific research, these two types of personality and nursing care professional type close to the individual through efforts, but also to adapt to nursing work. As the surveyed boys are first and second grade students, they have not started the study of professional subjects, so no difference in professional interest scores. 
Vocational interest is based on a certain social and professional needs, and in a certain learning and education under the conditions formed and developed, is doing their work motivation and foundation. Occupational interest reflects the individual's preference for the job, is one of the internal driving force of the individual engaged in occupation. Career interests can make people more familiar with and adapt to the occupational environment and professional roles. In fact, the vast majority of successful people are those who have both a certain skill, but also engaged in the work of people really interested in. Because in their own interests with the professional career, it is easier to obtain professional satisfaction, satisfaction itself is to motivate people to work hard. According to Holland's theory of career interest, interest is the most important factor in the process of individual and occupation matching, which is influenced by heredity and environment, but mainly influenced by the acquired environment. Career quality education and employment guidance is through the care of boys and nurses to recognize the importance of medical work, encourage them to love care.

Correlation regression analysis showed that the social type of personality characteristics and internal and external to a positive correlation, and neuroticism was negatively correlated, and the main factors affecting the career interest score is the extroversion. Outgoing personality of people encounter unpleasant, can take the initiative to find someone to tell, the release of pressure, thereby reducing the psychological pressure, is conducive to maintaining mental health. Nursing work is the face of people, extroverted personality who can take the initiative to communicate with patients, the establishment of a good nurse-patient relationship, and good nurse-patient relationship is the basis for nursing work. Big five factor theory, emotional stability of people failing to calmly, can calmly deal with emergencies. Nursing job is tense work, long-term with emotional work, is not conducive to the physical and mental health of nurses, is not conducive to the nursing work. At the same time, with a stable mood to understand the pain of others, more attentive care of patients, and patients with the recognition of nursing can not only greatly improve patient satisfaction, but also increase the professional accomplishment of nurses.

Correlation regression analysis showed that the social type of personality characteristics and internal and external to a positive correlation, and neuroticism was negatively correlated, and the main factors affecting the career interest score is the extroversion. Outgoing personality of people encounter unpleasant, can take the initiative to find someone to tell, the release of pressure, thereby reducing the psychological pressure, is conducive to maintaining mental health. Nursing work is the face of people, extroverted personality who can take the initiative to communicate with patients, the establishment of a good nurse-patient relationship, and good nurse-patient relationship is the basis for nursing work. Big five factor theory, emotional stability of people failing to calmly, can calmly deal with emergencies. Nursing job is tense work, long-term with emotional work, is not conducive to the physical and mental health of nurses, is not conducive to the nursing work. At the same time, with a stable mood to understand the pain of others, more attentive care of patients, and patients with the recognition of 
nursing can not only greatly improve patient satisfaction, but also increase the professional accomplishment of nurses.

\section{Conclusion}

Nursing undergraduate nursing students are still undergraduate students to adjust and employment-based high. The increasing demand for male nurses and employment pressure on boys is to choose to attend nursing, nursing careers performance motivation of career choice. Career undergraduate boys vocational interest to social type, and care professional match. The personality characteristics of excellent nurses are good cooperation, strong social activity ability, strong adaptability, optimistic, satisfied, cheerful, self-confident, good mental state, and social personality close to that of nursing boys with excellent Nurses some of the personality characteristics, is conducive to its role by the student to the nurse changes. Nursing boys overall personality tends to extroverted, optimistic and active, but emotional instability, emotional easy to expose, good impulse, a cover tendency. But the personality characteristics of neuroticism and mental quality score are higher than the norm, the need to adjust their mental health education mentality, to promote the improvement of their own personality.

\section{References}

[1] Chen Shuchong. Analysis of the factors affecting the career choice of college students. Neijiang Science and Technology, 10(3), pp. 27-31, 2009.

[2] the impact of male nursing career development of the relevant factors and countermeasures .Li Guiling. China Practical Medicine, 8(3), pp. 31-33, 2009.

[3] Wang Kaifu. Free normal students career planning factors and countermeasures.. Journal of Chongqing Electronic Engineering Career College, 2(4), pp. 19-25, 2009.

[4] Wan Meiling, Wang Huizhen, Liu Honghua, Gao Yulin. Nursing undergraduates personal career planning status survey. Journal of Nursing, 1(5), pp. 18-22, 2009.

[5] Wang Yonggen. Analysis of vocational college students career planning factors. Education and occupation, 36(2), pp. 87-89, 2008. 